\title{
Impact of surgery on pain, disability, and quality of life of patients with degenerative lumbar disease: Brazilian data
}

\author{
Impacto da cirurgia na dor, incapacidade e qualidade de vida de portadores de doença \\ degenerativa lombar: dados brasileiros
}

Ruy Gil ROHRMOSER', Albert V. BRASIL', Guilherme GAGO², Marcelo P. FERREIRA', Paulo Valdeci WORM'1, Jorge L. KRAEMER', Nelson P. FERREIRA'

\begin{abstract}
Objective: To study the impact of surgery on pain, disability, quality of life, and patient satisfaction in a sample of patients with Degenerative Lumbar Disease (DLD). Methods: Retrospective analysis of prospectively collected data. Comparison between pre and postoperative (6 - 12 months) ODI and SF-36, plus postoperative Patient Satisfaction Index. Results: From a total of 216 patients included, improvement was observed in average scores of pain (201.2\%), disability (39.7\%), physical quality of life (42\%), and mental quality of life (37.8\%). Among these patients, $57.7 \%$ reached or surpassed the minimal clinically important difference (MCID) for ODI, 57.7\% for the SF-36 pain component, $59.7 \%$ for the SF-36 physical component summary, and 50.5\% achieved or surpassed the MCID for the SF-36 mental component summary. Conclusions: Surgery produced a significantly positive impact on pain, disability, and quality of life of patients. Overall, $82.5 \%$ of the patients were satisfied.
\end{abstract}

Keywords: spine surgery; intervertebral disc degeneration; outcome assessment (health care); disability; pain; quality of life; lumbar vertebrae; treatment outcomes; patient satisfaction; patient reported outcomes.

\section{RESUMO}

Objetivo: Descrever o impacto da cirurgia na dor, incapacidade, qualidade de vida e a satisfação global do paciente numa amostra unificada de pacientes portadores de DDL. Métodos: Análise retrospectiva de dados colhidos prospectivamente em pacientes operados no período de janeiro de 2014 a março de 2017, que tivessem avaliação pré-operatória e pelo menos uma avaliação pós-operatória entre 6 e 12 meses com os questionários de ODI, SF-36 e o ISP. Resultados: Um total 216 pacientes preenchia os critérios de inclusão. Houve melhora no escore médio de dor (201,2\%), incapacidade (39,7\%), qualidade de vida física (42\%) e mental (37,8\%). Da amostra, 57,7\% alcançaram o MCID de dor, $59,7 \%$ de ODI, 59,7\% 50,5\% de PCS e 50,5\% de MCS; $82,5 \%$ dos pacientes se consideraram "Satisfeitos". Conclusões: O efeito da cirurgia foi amplamente favorável na dor, incapacidade e qualidade de vida dos pacientes portadores de DDL. Estes dados podem servir de guia para aconselhamento pré-operatório quanto às perspectivas de sucesso.

Palavras-chave: cirurgia da coluna vertebral; degeneração de disco intervertebral; avaliação de resultados (cuidados de saúde); deficiência; dor; qualidade de vida; vértebras lombares; resultado do tratamento; satisfação do paciente; resultados relatados por paciente

Disc herniation, spinal stenosis, spondylolisthesis, and degenerative spinal deformity are collectively referred to as Degenerative Lumbar Disease (DLD), corresponding to the most frequent reason for elective spine surgery ${ }^{1,2,3}$. Although the number of surgical procedures for DLD treatment continues to increase, the interpretation of their results remains controversial ${ }^{4}$. The patients usually describe their expectations in absolute, broad terms, and the results are consequently described only as either "success" or "failure". DLD, however, affects health on several levels, including pain, disability, physical quality of life, and mental quality of life. These components can be evaluated using Patient Reported

${ }^{1}$ Hospital São José, Irmandade Santa Casa de Misericórdia de Porto Alegre (ISCMPA), Departamento de Neurocirurgia, Porto Alegre RS, Brasil;

Universidade Católica de Pelotas (UCPel), Pelotas RS, Brasil.

Nelson P. Ferreira (iD) https://orcid.org/0000-0003-3139-3276

Correspondence: Albert Vincent Berthier Brasil; Rua Germano Petersen Jr., 101/ Conj. 909; $90540-140$ Porto Alegre, Rio Grande do Sul, Brasil; E-mail: albertvb@terra.com.br

Conflict of interest: There is no conflict of interest to declare.

Funding: MD Ruy Gil Rohrmoser is supported by an AOSpine Foundation Fellowship Grant.

Received 12 December 2017; Received in final form 15 April 2019; Accepted 01 June 2019. 
Outcome Measures (PROM) questionnaires ${ }^{5}$. The lack of consensus on the impact of surgical treatment of DLD is due to the diversity of possible outcomes in the components as mentioned above. Since there is an occasional improvement in only some of them ${ }^{6}$, the subjective satisfaction of each patient regarding the results of the surgery should also be analyzed. International ${ }^{7,8,9,10}$ and Brazilian ${ }^{11}$ literature reports results on each of the subtypes of DLD separately. However, the patients often present different clinical conditions at the same time, including disc herniation and stenosis, stenosis in one level and spondylolisthesis in another, and so on. Recently, studies evaluating the results of surgery for DDL analyzing all patients as a single set have been published, an approach that seems realistic ${ }^{12,13,14}$.

Preoperative counseling in DLD, as in any surgically treatable disease, ought to include information on the prognosis of success and failure. This task becomes challenging when there is no consensus on what constitutes success and failure per se. The low availability of data collected in our country adds difficulty to Brazilian surgeons. Thus, with the aim of providing future information for preoperative counseling, the present work describes observed variations in pain, disability, and quality of life from a sample of DLD patients surgically treated in Brazil. We also report overall patient satisfaction according to surveys.

\section{METHODS}

A retrospective analysis was conducted on clinical results prospectively collected from DLD patients surgically treated at the Neurosurgery service at São José Hospital, Santa Casa de Misericórdia Hospital Complex (ISCMPA) in Porto Alegre, Brazil, between June 2013 and April 2017. The patients were asked to fill out the Oswestry Disability Index (ODI) ${ }^{15}$ and the Short Form 36 health survey (SF-36) ${ }^{16}$ questionnaires during the preoperative assessment. These same questionnaires were applied in the postoperative assessments at the first, sixth and $12^{\text {th }}$ months after surgery, along with the Patient Satisfaction Index (PSI) questionnaire (Figure). All DLD patients for whom preoperative and postoperative ( from six to 12 months after surgery) data were available were included

\begin{tabular}{|c|c|}
\hline $\begin{array}{c}\text { Patient Satisfaction } \\
\text { Index }\end{array}$ & $\begin{array}{c}\text { Would you consider to undergo again to } \\
\text { surgery to achieve the same result? }\end{array}$ \\
\hline 5 & Undoubtedly yes \\
\hline 4 & Probably yes \\
\hline 3 & I am unsure \\
\hline 2 & Probably not \\
\hline 1 & Undoubtedly not \\
\hline
\end{tabular}

Figure. Patient Satisfaction Index (PSI). in our analysis. ODI scores were estimated following the original recommendations ${ }^{13}$. SF-36 scores were grouped in three constructs: physical component summary (PCS), mental component summary (MCS), and pain (PAIN) ${ }^{16,17}$. The minimal clinically important difference (MCID) score was estimated as described by Copay ${ }^{18,19}$, primarily based on the satisfaction group 4 of the PSI. Patients in groups 4 and 5 of the PSI were grouped as "satisfied" for discussion purposes.

This research was approved by the Ethics and Research Committee at ISCMPA, and all patients signed a term of informed consent.

\section{Statistical analysis}

The variables are presented as mean (M) and SE values, or absolute (n) and relative (\%) frequencies. Patients were divided into two groups: i) satisfied, who presented a PSI of 5 or 4 (who would undergo surgery again); and ii) dissatisfied, who filed a PSI of 3, 2 or 1 (who would not undergo surgery again or are unsure). Chi-square and t-tests were used to compare variables and define groups. The statistical analyses were performed using SPSS software version 20.0.

\section{RESULTS}

A total of 444 patients underwent surgery for treatment of DLD during the data sampling period. Among these patients, 216 filled in the inclusion criteria as described in the methods section, and were included in the analysis sample.

The characteristics of the patients included and excluded in the final analysis are presented in Table 1. No significant differences between the groups were observed. In the studied group, 115 patients $(53.2 \%)$ were female. The mean age was $52.6+/-14.4$ (SD) year old. Surgical instrumentation was required in 83 cases $(38.4 \%)$. Eighty patients (37.0\%) were from the Unified Health System (Sistema Único de Saúde, SUS), and 136 (63.0\%) from private health plans. A total of 21 patients presented Diabetes Mellitus (9.8\%), 76 (35.3\%) were hypertense, and four (1.9\%) presented alcoholism. At the

Table 1. Comparison between patients included and excluded.

\begin{tabular}{|c|c|c|c|}
\hline Scale & $\begin{array}{l}\text { Excluded } \\
(n=228)\end{array}$ & $\begin{array}{l}\text { Included } \\
(n=216)\end{array}$ & $p$-value \\
\hline \multicolumn{4}{|c|}{ Clinical characteristics } \\
\hline Age (in years) & $51.4 \pm 1.0$ & $52.6 \pm 1.0$ & 0.38 \\
\hline Body Mass Index & $27.4 \pm 0.3$ & $27.0 \pm 0.3$ & 0.44 \\
\hline \multicolumn{4}{|c|}{ Pre-operative of the evaluated scales } \\
\hline SF-36 PCS & $28.1 \pm 0.5$ & $28.6 \pm 0.4$ & 0.45 \\
\hline SF-36 MCS & $39.8 \pm 1.0$ & $40.5 \pm 1.0$ & 0.64 \\
\hline SF-36 BP & $20.7 \pm 1.0$ & $29.6 \pm 1.0$ & 0.18 \\
\hline ODI & $27.3 \pm 0.05$ & $26.8 \pm 0.06$ & 0.55 \\
\hline
\end{tabular}

SF-36: short form-36; PCS: physical component summary; MCS: mental component summary; BP: Bodily Pain; ODI: Oswestry Disability Index. 
time of surgery, 53 (24.5\%) were on medication for depression and 34 (15.8\%) for anxiety. Previous lumbar spine surgery had been performed on 23 patients (10.9\%), and 30 (13.9\%) were submitted to surgery through minimally invasive methods during this period.

Our initial protocol assumed that patients would be operated upon for one single subtype of DLD. According to this protocol, the patients where distributed as follows: lumbar disc herniation ( $\mathrm{n}=98,5 \%$ ); foraminal and/or extraforaminal disc herniation ( $\mathrm{n}=16,7.5 \%)$; lumbar stenosis $(\mathrm{n}=55$, $25.8 \%$ ); spondylolisthesis ( $\mathrm{n}=35,16.4 \%$ ); lumbar degenerative deformity $(n=9,4 . \%)$. When the surgical technique used on each case was reviewed, it became evident that a large part of the sample harbored more than one subtype of DLD (for example: disc herniation on one level and stenosis on another, spondylolisthesis on one level and disc herniation or stenosis on another, and so on). Therefore, we believe these numbers are unreliable.

The PSI questionnaire scores ranked 113 patients (53.5\%) as satisfaction level 5 (definitely would undergo surgery again), and 61 (28.9\%) as level 4 (probably would undergo surgery again). The combination of these two categories indicates that 174 patients $(82.5 \%)$ could be described as „satisfied“ with the outcome. The „dissatisfied" patients amounted to 37 (17.5\%), of which $23(10.9 \%)$ were included in satisfaction level 3 (unsure about undergoing surgery again), nine (4.3\%) in satisfaction level 2 (probably would not undergo surgery again), and five (2.4\%) in satisfaction level 1 (definitely would not undergo surgery again) (Table 2).

The MCID scores for pain (pain component SF-36), disability (ODI), and quality of life (SF-36 PCS and SF-36 MCS) were, respectively, 24.5 (3.2), 8.4 (1.3), 6.8 (1.2), and 7.6 (2.5).

Table 2 presents the average raw scores, mean variation between pre- and postoperative assessment scores (D), average percentage variation (D\%), and percentage of patients who reached the MCID for the ODI, SF-36 pain component, SF-36 PCS, and SF-36 MCS. These scores are presented for the entire patient group at pre and postoperative conditions. Table 2 also shows the number and percentage of patients in each of the five categories of the PSI. Mean values, D, D\% and $\%$ of the subgroup who reached MCID in each PROM and corresponding PSI are also indicated in Table 2. The scores are presented as mean + standard error (SE).

Table 3 shows a comparison of the satisfied (groups 5 and 4) and dissatisfied patients (groups 3,2 and 1) regarding their average raw scores, mean variation between pre and postoperative assessment scores (D), average percentage variation (D\%), and percentage of patients who reached the MCID for the ODI, SF-36 pain component, SF-36 PCS, and SF-36 MCS. The scores are presented as mean + standard error (SE).

Table 2. Results of Pain, ODI, SF-36 PCS and SF-36 MCS according to the Patient Satisfaction Index (PSI).

\begin{tabular}{|c|c|c|c|c|c|c|c|}
\hline \multirow{3}{*}{ Evaluated scales } & \multicolumn{2}{|c|}{ Total } & \multicolumn{5}{|c|}{ PSI* } \\
\hline & Pre-operative & Post-operative & $5 * *$ & $4^{* *}$ & 3 & 2 & 1 \\
\hline & $(n=216)$ & $(n=216)$ & $(n=113)$ & $(n=61)$ & $(n=23)$ & $(n=9)$ & $(n=5)$ \\
\hline Pain SF average raw score & $22.6 \pm 1.0$ & $54.5(1.7)$ & $64.1(2.3)$ & $48.6(2.7)$ & $32.5(4.1)$ & $37.2(8.0)$ & $43.4(9.1)$ \\
\hline D Pain SF & & $31.9(1.8)$ & $40.5(2.5)$ & $24.5(3.2)$ & $15.6(4.5)$ & $21.8(8.1)$ & $19.6(8.9)$ \\
\hline D\% Pain SF & & $201.3(2.1)$ & $239.0(0.2)$ & $173.0(0.2)$ & $135.1(0.4)$ & $171.7(0.8)$ & $83.8(0.4)$ \\
\hline (\% of the subgroup reaching MCID) & & $123(57.7 \%)$ & $82(73.2 \%)$ & $27(45.8 \%)$ & $6(26.1 \%)$ & $3(33.3 \%)$ & $2(40.0 \%)$ \\
\hline ODI average raw score ${ }^{\dagger}$ & $26.8 \pm 0.6$ & $15.1(0.7)$ & $11.1(0.9)$ & $18.2(1.0)$ & $22.3(1.5)$ & $22.9(3.6)$ & $19.6(4.2)$ \\
\hline D ODI & & $-11.5(0.8)$ & $-15.0(1.1)$ & $-8.4(1.3)$ & $-7.4(2.0)$ & $-6.6(2.5)$ & $-3.0(5.3)$ \\
\hline D\% ODI & & $-39.7(2.7)$ & $-55.2(3.4)$ & $-22.7(6.3)$ & $-21.2(5.4)$ & $-23.5(8.9)$ & $\begin{array}{l}-10.8 \\
(19.5)\end{array}$ \\
\hline (\% of the subgroup reaching MCID) & & $116(57.7 \%)$ & $73(69.5 \%)$ & $30(53.6 \%)$ & $8(36.4 \%)$ & $2(22.2 \%)$ & $1(25.0 \%)$ \\
\hline PCS average raw scores ${ }^{\ddagger}, \S$ & $28.6 \pm 0.4$ & $38.4(0.7)$ & $41.8(1.0)$ & $35.5(1.0)$ & $32.6(1.9)$ & $36.1(3.42)$ & $\begin{array}{l}35.21 \\
(2.77)\end{array}$ \\
\hline D PCS & & $10.0(0.8)$ & $13.7(1.1)$ & $6.8(1.2)$ & $3.2(2.07)$ & $8.4(3.9)$ & $8.8(2.8)$ \\
\hline D\% PCS & & $42.0(3.5)$ & $\begin{array}{l}56.31 \\
(5.24)\end{array}$ & $\begin{array}{l}30.62 \\
(5.87)\end{array}$ & $\begin{array}{l}17.91 \\
(9.62)\end{array}$ & $\begin{array}{l}36.28 \\
(13.6)\end{array}$ & $33.4(10.4)$ \\
\hline (\% of the subgroup reaching MCID) & & $117(59.7 \%)$ & $72(72.0 \%)$ & $29(50.0 \%)$ & $8(38.1 \%)$ & $5(62.5 \%)$ & $2(40 \%)$ \\
\hline MCS average raw score ${ }^{\ddagger}$ & $40.5 \pm 1.0$ & $49.2(1.0)$ & $53.0(1.24)$ & $47.0(2.0)$ & $42.00(3.7)$ & $37.4(5.9)$ & $45.7(7.7)$ \\
\hline DMCS & & $8.7(1.2)$ & $10.8(1.5)$ & $7.6(2.5)$ & $7.9(3.9)$ & $2.6(5.9)$ & $-3.6(8.4)$ \\
\hline $\mathrm{D} \% \mathrm{MCS}$ & & $37.8(0.05)$ & $40.8(0.06)$ & $39.1(0.09)$ & $44.8(0.2)$ & $12.3(0.2)$ & $-3.9(0.2)$ \\
\hline (\% of the subgroup reaching MCID) & & $99(50.5 \%)$ & $56(56 \%)$ & $30(51.7 \%)$ & $8(38.1 \%)$ & $2(25.0 \%)$ & $2(50.0 \%)$ \\
\hline
\end{tabular}

ODI: Oswestry Disability Index; SF-36: short form-36; PCS: physical component summary; MCS: mental component summary; MCID: minimal clinically important difference; * PSI data was not available for five patients; ${ }^{~}$ seven patients did not fill out the ODI questionnaire; ${ }^{2} 2$ patients did not fill out the SF-36 PCS and SF36 MCS questionnaire; $\$$ three patients did not fill out the SF-36 pain component questionnaire; ** For the descriptive analysis, we considered the combination of groups 4 and 5 as the patients who would undergo surgery again (satisfied). 
Table 3. Comparison between the satisfied and dissatisfied groups using the scores of the Oswestry Disability Index (ODI), and physical component summary (PCS), mental component summary (MCS) and Pain constructs of the SF-36.

\begin{tabular}{|c|c|c|c|}
\hline \multirow{2}{*}{ Evaluated scales } & \multicolumn{2}{|c|}{ Grouped Patient Satisfaction Indexes } & \multirow{2}{*}{$\mathrm{p}$-value } \\
\hline & 5 or $4(n=174)$ & 3,2 or $1(n=34)$ & \\
\hline ODI average raw score & $13.6 \pm 0.7$ & $22.0 \pm 1.4$ & $<0.001$ \\
\hline D ODI & $-12.7 \pm 0.9$ & $-6.7 \pm 1.5$ & 0.003 \\
\hline D\% ODI & $-43.9 \pm 3.3$ & $-20.6 \pm 4.5$ & 0.002 \\
\hline (\% of the subgroup reaching $\mathrm{MCID}$ ) & $103(64 \%)$ & $11(31.4 \%)$ & $<0.001$ \\
\hline PCS average raw score & $39.5 \pm 0.8$ & $33.8 \pm 1.5$ & 0.002 \\
\hline D PCS & $11.2 \pm 0.9$ & $5.3 \pm 1.6$ & 0.004 \\
\hline D\% PCS & $46.9 \pm 4.1$ & $24.5 \pm 6.9$ & 0.018 \\
\hline (\% of the subgroup reaching $\mathrm{MCID}$ ) & $101(63.9 \%)$ & $15(44.1 \%)$ & 0.032 \\
\hline MCS average raw score & $50.8 \pm 1.1$ & $41.4 \pm 2.9$ & 0.001 \\
\hline DMCS & $9.7 \pm 1.3$ & $5.0 \pm 3.1$ & 0.146 \\
\hline D\% MCS & $40.2 \pm 5.3$ & $30.0 \pm 16.0$ & 0.458 \\
\hline (\% of the subgroup reaching MCID) & $86(54.4 \%)$ & $11(32.4 \%)$ & 0.020 \\
\hline Pain SF average raw score & $58.8 \pm 1.9$ & $35.1 \pm 3.4$ & $<0.001$ \\
\hline D Pain SF & $35.0 \pm 2.0$ & $17.7 \pm 3.5$ & $<0.001$ \\
\hline D\% Pain SF & $216.3 \pm 0.2$ & $137.1 \pm 32.6$ & 0.043 \\
\hline (\% of the subgroup reaching $\mathrm{MCID}$ ) & $109(63.7 \%)$ & $11(29.7 \%)$ & $<0.001$ \\
\hline
\end{tabular}

\section{DISCUSSION}

The data from the present study showed that $82.5 \%$ of the patients undergoing surgical treatment for DLD were satisfied with the result of the surgery between six and 12 months after the intervention, i.e., they would consider undergoing surgery again to achieve the same results.

The impact of surgery in our case study was positive since there was an improvement in the average scores of pain (201.3\%), disability (39.7\%), physical quality of life (42\%), and mental quality of life (37.8\%). Our data revealed that $57.7 \%$ reached or surpassed the MCID for the ODI, $57.7 \%$ for the SF-36 pain component, $59.7 \%$ for the SF-36 PCS, and 50.5\% achieved or surpassed the MCID for the SF-36 MCS (Table 2).

Pain relief is usually the primary goal of patients who elect surgical treatment for DLD. The quality of life scores associated with pain (SF-36 pain component) for the general Brazilian population is $76.7^{20}$, while for our sample, the average preoperative score was 22.6, showing the significant impact of pain on their quality of life. After surgery, the average scores increased to 54.4. If we subdivide the patients according to their postoperative satisfaction, these scores improve significantly in satisfaction groups 5 (64.1), 4 (48.6), and 4+5 (58.8), although they remain below the global Brazilian average ${ }^{20}$. The MCID for the SF-36 pain component was reached by $73.2 \%$ of the patients in the satisfaction group 5 , and by $63.7 \%$ of the patients in the group $4+5$. It should be noted that the use of the SF-36 pain component to evaluate treatment results is not widespread in the literature; most often, the reported scores are based on the visual analogue scale (VAS) $)^{21,22,9,23,8}$ and numerical rating scale (NRS) ${ }^{13,24,7,10,12}$. However, a few authors have recently been opting for the SF-36 pain component ${ }^{25}$. An advantage of this approach is the fact that this pain score is based on two questions, both referring to the impact of pain on the patient's quality of life $^{16}$, which may improve its reliability.

A patient with an ODI score less than or equal to 20 is considered as presenting "no disability". For ODI scores between 20 and 40, patients are considered to be "mildly disabled". ${ }^{15}$ The mean score for preoperative ODI in our sample was 26.0, placing the average DLD patient who elected lumbar surgery treatment in the latter group. After treatment, the average disability degree was reduced in $39.6 \%$. Final mean values were less than 20 in satisfaction groups 5 (11.0), 4 (18.2), and 4+5 (13.6). The MCID for ODI was reached by $69.5 \%$ of the patients in the satisfaction group $5,53.6 \%$ of the patients in the satisfaction group 4, and $64 \%$ of the patients in the group $4+5$. Therefore, the absolute majority of the satisfied patients ( $82 \%$ of the sample) recovered to a "no disability" state after surgery. Patients in the satisfaction groups 3 and 2 presented average values within the range of disability, whereas patients in the group 1 were in borderline ranges. In other studies where preoperative ODI scores were assessed, some reports included higher scores than the ones reported here ${ }^{24,26,27}$, whereas other reports were closer to our results ${ }^{12,14}$. Some authors described the improvement in disability based on the percentage of the patients reaching the MCID for ODI ${ }^{6,13}$, while others took into consideration the average variation of the disability score ${ }^{12,28,8,27}$. The percentage improvement for our 
dataset was around 40\%, which is similar to the reports for other patient sets ${ }^{29}$, as well as an increase of 11.5 points ${ }^{26,7}$.

The mean score for the physical quality of life component (SF-36 PCS) for the general Brazilian population is $49.3^{20}$. The mean preoperative PCS score for the present case study was 28.6, which is significantly lower. Even though the surgical treatment allowed for an increase of 10.0 score points and an improvement of $42 \%$ in the studied group, the final score for SF-36 PCS (38.4) was still below the average for the general Brazilian population. For patients of the satisfaction groups 4+5, 63.9\% reached MCID.

Although DLD is a primarily physical problem, the mental quality of life of patients suffering from this disease is significantly impaired. It is sometimes believed that mental aspects might be boosting or causing pain, therefore justifying the failure of physical treatments ${ }^{5}$. The preoperative score for the mental component (SF-36 MCS) for the present patient sample was 40.5 , which is significantly lower than the average for the general Brazilian population (51.1). However, a significant improvement was observed after treatment, with an average postoperative score of 49.2. Considering the "satisfied" group ( $82 \%$ of the total sample), the average postoperative score was 50.80 , which is very close to the average for the general population ${ }^{20}$. Our findings suggest that pain and disability resulting from DLD impaired the mental quality of life before surgery and that surgical treatment led to its significant improvement (Table 2).

The meaning of a "satisfactory result" for DLD is still controversial. Several authors have arbitrarily defined what they would consider as being a "satisfied" patient. In the present work, we opted to consider the patients from satisfaction levels 4 and 5 as "satisfied". The comparisons between groups $5+4$ ("satisfied") and 3+2+1 ("dissatisfied") revealed significant differences in virtually all parameters analyzed (Table 3 ), supporting our choice of group 4 as a threshold.

A few caveats were detected in the course of this study: first, only about $50 \%$ of the patients could be included in the study due to lack of follow-up, which is a common problem in DLD studies. However, for the present work, as well as in other previous reports ${ }^{22,30}$, data from the included patient group did not seem to present significant differences as compared to data from the excluded patients (Table 1). Second, the use of the SF-36 pain component score instead of VAS or NRS impacted our ability to compare our results with those obtained in previous studies. Even if one assumes that the "Pain component" of the SF-36 allows for a more precise estimate of the pain level than the $\mathrm{VAS}^{25}$ this problem still deserves to be mentioned.

Finally, the clustering of different pathologies under a single group (i.e., DLD) could be criticized. A clear distinction between cases that exclusively harbor disc herniations, stenosis, spondylolisthesis or deformity may be challenging when we consider a large sample ${ }^{7}$. Our database was set up with the aim of presenting a clear-cut distinction between these four subtypes of DLD. As the study developed, however, overlapping of different pathologic subtypes in the same patient became so frequent as to justify studying the group as a whole. A tendency to combine data for the different types of DLD for such analyses has also been observed in other recent publications ${ }^{12-14}$.

In conclusion, surgical treatment for DLD presented widely positive results, as demonstrated by the following improvement statistics: a) $201 \%$ improvement in painrelated quality of life scores, with $57.7 \%$ of the patients reaching MCID; b) 39.6\% improvement in disability, with $57.7 \%$ of the patients reaching MCID; c) $42 \%$ improvement in physical quality of life scores, with $59.7 \%$ of the patients reaching MCID; and d) $37.8 \%$ improvement in mental quality of life, with $50.5 \%$ of the patients reaching MCID. Based on these developments, about $82.5 \%$ of the patients declared themselves as satisfied with the outcomes of the surgery.

\section{Acknowledgments}

The authors thank AOSpine for the financial support, Karlyse Belli for the statistical analyses, and Claudia Barroso for the data collection.

\section{References}

Street JT, Lenehan BJ, Dipaola CP, et al. Morbidity and mortality

of major adult spinal surgery: a prospective cohort analysis

of 942 consecutive patients. Spine J. 2012;12(1):22-34.

https://doi.org/10.1016/j.spinee.2011.12.003.

2. Brasil AVB, Teles AR, Roxo MR, et al. A simple scoring system

for predicting early major complications in spine surgery: the cumulative effect of age and size of surgery. Arq Neuropsiquiatr. 2016;74(10):803-809. https://doi.org/10.1590/0004-282X20160127.

3. Campbell PG, Jennifer Malone CRNP, Yadla S, et al. Comparison of ICD-9-based, retrospective, and prospective assessments of perioperative complications: assessment of accuracy in reporting. J Neurosurg Spine. 2011;14:16-22. https://doi.org/10.3171/2010.9.SPINE10151.
4. Yoshihara H, Yoneoka D. National trends in the surgical treatment for lumbar degenerative disc disease: United States, 2000 to 2009. Spine J. 2015;15(2):265-271. https://doi.org/10.1016/j.spinee.2014.09.026.

5. Teles AR, Khoshhal KI, Falavigna A. Why and how should we measure outcomes in spine surgery? J Taibah Univ Med Sci. 2016;11(2):91-97. https://doi.org/10.1016/j.jtumed.2016.01.003.

6. Copay AG, Martin MM, Subach BR, et al. Assessment of spine surgery outcomes: inconsistency of change amongst outcome measurements. Spine J. 2010;10(4):291-296. https://doi.org/10.1016/j.spinee.2009.12.027.

7. Glassman SD, Carreon LY, Djurasovic M, et al. Lumbar fusion outcomes stratified by specific diagnostic indication. Spine J. 2009;9(1):13-21. https://doi.org/10.1016/j.spinee.2008.08.011. 
8. Parker SL, Adogwa O, Paul AR, et al. Utility of minimum clinically important difference in assessing pain, disability, and health state after transforaminal lumbar interbody fusion for degenerative lumbar spondylolisthesis. J Neurosurg Spine. 2011;14(May):598-604. https://doi.org/10.3171/2010.12.SPINE10472.

9. Parker SL, Mendenhall SK, Shau D, et al. Determination of minimum clinically important difference in pain, disability, and quality of life after extension of fusion for adjacentsegment disease. J Neurosurg Spine. 2012;16(January):61-67. https://doi.org/10.3171/2011.8.SPINE1194.

10. Werner DAT, Grotle M, Gulati S, et al. Criteria for failure and worsening after surgery for lumbar disc herniation: a multicenter observational study based on data from the Norwegian Registry for Spine Surgery. Eur Spine J. 2017:26(10):2650-2659. https://doi.org/10.1007/s00586-017-5185-5.

11. Rodrigues LF, Voloch P, Gurgel S, Cavallari F. Avaliação retrospectiva por meio do questionário SF-36 de pacientes submetidos à estabilização dinâmica pedicular para o tratamento de doenças degenerativas lombares. Columna. 2010;9(2):104-112.

12. Mcgirt MJ, Bydon M, Archer KR, et al. An analysis from the Quality Outcomes Database, Part 1. Disability, quality of life, and pain outcomes following lumbar spine surgery: predicting likely individual patient outcomes for shared decision-making. J Neurosurg Spine. 2017;27(4):357-369. https://doi.org/10.3171/2016.11.SPINE16526.

13. Parker SL, Asher AL, Godil SS, Devin CJ, Mcgirt MJ. Patientreported outcomes 3 months after spine surgery: is it an accurate predictor of 12-month outcome in real-world registry platforms? Neurosurg Focus. 2015;39(December):1-7. https://doi.org/10.3171/2015.9.FOCUS15356.

14. Hooff ML Van, Mannion AF, Staub LP, Ostelo RWJG, Fairbank JCT. Determination of the Oswestry Disability Index score equivalent to a "satisfactory symptom state" in patients undergoing surgery for degenerative disorders of the lumbar spine - a Spine Tango registry-based study. Spine J. 2016;16(10):1221-1230. https://doi.org/10.1016/j.spinee.2016.06.010.

15. Fairbank JCT, Pynsent PB. The Oswestry Disability Index. Spine (Phila Pa 1976). 2000;25(22):2940-2953.

16. Ware JE. SF-36 Health Survey Update. Spine (Phila Pa 1976). 2000;25(24):3130-3139.

17. Ware JE, Kosinski M, Keller SD. Sf-36 Physical and Mental Health Summaries Scales: A User's Manual. Lincoln RI: QualityMetrics 1994.

18. Copay AG, Glassman SD, Subach BR, Berven S, Schuler TC, Carreon LY. Minimum clinically important difference in lumbar spine surgery patients: a choice of methods using the Oswestry Disability Index, Medical Outcomes Study questionnaire, Short Form 36, and Pain Scales. Spine J. 2008;8(6):968-974. https://doi.org/10.1016/j.spinee.2007.11.006.

19. Copay AG, Subach BR, Glassman SD, Polly DW, Schuler TC. Understanding the minimum clinically important difference: a review of concepts and methods. Spine J. 2007;7:541-546. https://doi.org/10.1016/j.spinee.2007.01.008.
20. Laguardia J, Campos MR, Travassos C, Najar AL, Anjos LA dos, Vasconcellos MM. Dados normativos brasileiros do questionário Short Form-36 Brazilian normative data for the Short Form 36 questionnaire, version 2. Rev Bras Epidemiol. 2013;16(4):889-897.

21. Parker SL, Mendenhall SK, Shau DN, et al. Minimum clinically important difference in pain, disability, and quality of life after neural decompression and fusion for same-level recurrent lumbar stenosis: understanding clinical versus statistical significance. J Neurosurg Spine. 2012;16(May):471-478.

22. Solberg TK, Sjaavik K, Ingebrigtsen T. Would loss to follow-up bias the outcome evaluation of patients operated for degenerative disorders of the lumbar spine? A study of responding and non-responding cohort participants from a clinical spine surgery registry. Acta Orthop. 2011;82(1):56-63. https://doi.org/10.3109/17453674.2010.548024.

23. Glassman S, Gornet MF, Branch C, et al. MOS Short Form 36 and Oswestry Disability Index outcomes in lumbar fusion: a multicenter experience. Spine J. 2006;6:21-26. https://doi.org/10.1016/j.spinee.2005.09.004.

24. Solberg T, Johnsen LG, Grotle M. Can we define success criteria for lumbar disc surgery? Estimates for a substantial amount of improvement in core outcome measures. Acta Orthop. 2013;84(2):196-201. https://doi.org/10.3109/17453674.2013.786634.

25. Walsh TL, Mdt D, Hanscom B, Lurie JD, Weinstein JN. Is a condition-specific instrument for patients with low back pain / leg symptoms really necessary? The responsiveness of the Oswestry Disability Index, MODEMS, and the SF-36. Spine (Phila Pa 1976). 2003;28(6):607-615.

26. Carreon LY, Glassman SD, Djurasovic M, et al. Are preoperative health-related quality of life scores predictive of clinical outcomes after lumbar fusion? Spine (Phila Pa 1976). 2009;34(7):725-730.

27. Crawford CH, Carreon LY, Bydon M, Asher AL, Glassman SD. Impact of preoperative diagnosis on patient satisfaction following lumbar spine surgery.J Neurosurg Spine. 2017;26(June):709-715. https://doi.org/10.3171/2016.11.SPINE16848.

28. Parker SL, Mcgirt MJ. Determination of the Minimum Improvement in Pain, Disability, and Health State Associated With Cost-Effectiveness: Introduction of the Concept of Minimum Cost-Effective Difference. Neurosurgery. 2012;71(6):1149-1155. https://doi.org/10.1227/NEU.0b013e318271ebde.

29. Glassman SD, Copay AG, Berven SH, Polly DW, Subach BR, Carreon LY. Defining Substantial Clinical Benefit Following Lumbar Spine Arthrodesis. J Bone Jt Surg Am. 2008;90:1839-1847. https://doi.org/10.2106/JBJS.G.01095.

30. Højmark K, Støttrup C, Carreon L, Andersen MO. Patient-reported outcome measures unbiased by loss of follow-up. Single-center study based on DaneSpine, the Danish spine surgery registry. Eur Spine J. 2016;25:282-286. https://doi.org/10.1007/s00586-015-4127-3. 